\title{
3D-Printed Graphene-Based Bow-Tie Microstrip Antenna Design and Analysis for Ultra-Wideband Applications
}

\author{
Emine Avşar Aydın
}

check for updates

Citation: Avşar Aydın, E. 3D-Printed Graphene-Based Bow-Tie Microstrip Antenna Design and Analysis for Ultra-Wideband Applications. Polymers 2021, 13, 3724. https:// doi.org/10.3390/polym13213724

Academic Editor: Andreea-Teodora Iacob

Received: 1 October 2021

Accepted: 26 October 2021

Published: 28 October 202

Publisher's Note: MDPI stays neutral with regard to jurisdictional claims in published maps and institutional affiliations.

Copyright: (C) 2021 by the author. Licensee MDPI, Basel, Switzerland. This article is an open access article distributed under the terms and conditions of the Creative Commons Attribution (CC BY) license (https:/ / creativecommons.org/licenses/by/ $4.0 /)$.
Department of Aerospace Engineering, Adana Alparslan Türkeş Science and Technology University, Adana 01250, Turkey; eaydin@atu.edu.tr

\begin{abstract}
In this study, the effects of graphene and design differences on bow-tie microstrip antenna performance and bandwidth improvement were investigated both with simulation and experiments. In addition, the conductivity of graphene can be dynamically tuned by changing its chemical potential. The numerical calculations of the proposed antennas at $2-10 \mathrm{GHz}$ were carried out using the finite integration technique in the CST Microwave Studio program. Thus, three bow-tie microstrip antennas with different antenna parameters were designed. Unlike traditional production techniques, due to its cost-effectiveness and easy production, antennas were produced using $3 \mathrm{D}$ printing, and then measurements were conducted. A very good match was observed between the simulation and the measurement results. The performance of each antenna was analyzed, and then, the effects of antenna sizes and different chemical potentials on antenna performance were investigated and discussed. The results show that the bow-tie antenna with a slot, which is one of the new advantages of this study, provides a good match and that it has an ultra-bandwidth of $18 \mathrm{GHz}$ in the frequency range of 2 to $20 \mathrm{GHz}$ for ultra-wideband applications. The obtained return loss of $-10 \mathrm{~dB}$ throughout the applied frequency shows that the designed antennas are useful. In addition, the proposed antennas have an average gain of $9 \mathrm{dBi}$. This study will be a guide for microstrip antennas based on the desired applications by changing the size of the slots and chemical potential in the conductive parts in the design.
\end{abstract}

Keywords: antenna performance; bow-tie antenna; bandwidth; graphene; chemical potential; 3D printer

\section{Introduction}

Microstrip patch antennas are used in aviation and satellite communication, biomedical, radio, and wireless applications due to their important features such as reduced size, weight, and cost [1]. However, low efficiency and narrow bandwidth also can give rise to significant disadvantages [2]. Among the simplest methods of overcoming these deficits, the best-known methods increase the substrate's thickness and the conductive elements to be used [1-3]. The patch antennas typically have a narrow bandwidth, and using a thicker dielectric substrate widens it [4]; for achieving a bandwidth greater than $10 \%$, a capacitive probe is generally needed [5,6]. Moreover, bandwidth optimization can be achieved with thick substrates or stacked patch configuration, but these also cause noise. Unfortunately, stacked patch solutions can be obtained with a complex fabrication process, and with these methods, the layers' alignment can cause some problems, such as air gap formation [7-9].

The compactness of the microstrip antennas is an important feature [10]. Typically, patch antenna size is determined by its resonant size. However, it can be very large for some antennas in practical applications, especially at low frequencies, and it can increase the wireless device's size. Short-circuit walls [11] and pins [12], folded patches [13], or substrates with high dielectric permeability [14] can be used to produce compact antennas. However, shorting pins and walls require complex realization and can generate nonsymmetrical broad-edged radiation [15]. Folded patches can also be difficult to apply. 
Finally, materials with a high dielectric constant have insufficient radiation, and they reduce the bandwidth and are expensive.

Previously, two physicists at the University of Manchester in 2004 discovered that graphene could be obtained by isolating a one-atom-thick layer from graphite. The second one is a simple two-dimensional sheet shaped in a hexagonal pattern consisting of carbon atoms [16]. Since its discovery, graphene has been the material that has been studied by many researchers from different fields due to its many new and unique physical properties. Moreover, apart from having electrical mobility higher than $2.105 \mathrm{~cm}^{2} \mathrm{Vm}$, it has a unique quantum Hall effect, good flexibility, and excellent mechanical resistance, which provides many advantages for different areas such as nanoelectronics, material science, photovoltaics, and engineering. Another important feature is that it has a thermal conductivity of more than ten times copper [17]. Additionally, graphene is already used in biotechnology, antibacterial materials, disease diagnosis, drug delivery, and cancer targeting [18-20].

A reconfigurable antenna is defined as an antenna in which at least one of its features can be changed by external intervention after its production is completed. There are many ways of classification of these reconfigurable antennas. Here are a few examples in order: It can be listed as causing the antennas to be changed again (changing the current lines, changing the dielectric properties of the antenna elements, geometric deformation), having the elements that allow the change (diodes, transistors, etc.) or changing the geometric structures of the antennas again. Various techniques are used in antenna reconstruction methods. Some researchers use localized active components that allow changing half-point current or impedance lines [21], others apply mechanical remodeling in the antenna [22], and still, other researchers apply configurations using substrates with tunable properties [23]. Again, some techniques go the way of reconfiguring power supply networks or opting for excitation antenna arrays [24]. Developments in microelectronics, the discovery of electrically operable switches, and varactors have revealed important suggestions for the emergence of reconfigurable devices. However, the elements to be put into the configuration increase the device size and bring additional production costs. During the reconstruction process, the electromagnetic properties of an antenna can be changed by applying the properties of the materials in the antenna structure (such as permeability, electric-magnetic field effects) with external control without adding any elements. These antenna structures are mostly used in the patch or substrate parts that make up the antennas. Graphene is a great material because it has excellent optical and electronic properties [25-27] and also because its resonance properties can be easily changed by applying an external voltage [28-30].

Using graphene provides a great advantage to antenna designs because it has an efficient dynamic tuning [31,32]. The frequency-dependent surface conductivity of graphene can be easily changed by causing changes in its chemical potential due to applying a gate voltage. While this important feature of graphene provides an advantage in adjusting the resonance frequencies of antennas, this situation provides the chance to easily manufacture antennas that can be used, especially at microwave frequencies.

The frequency-dependent two-dimensional surface conductivity of single-layer graphene is expressed by the Kubo formula (Equation (1)) [33]:

$$
\sigma\left(\omega, \mu_{c}, \Gamma, T\right) \approx-j \frac{q_{e}^{2} k_{B} \mathrm{~T}}{\pi h^{2}(\omega-2 j \Gamma)} \times\left(\frac{\mu_{c}}{k_{B} \mathrm{~T}}+2 \ln \left(e^{-\frac{\mu_{c}}{k_{B} \mathrm{~T}}}+1\right)\right)
$$

$\omega$ : the angular frequency

$\mu_{c}$ : the chemical potential

$\Gamma$ : the scattering rate

$\mathrm{T}$ : the temperature

$\tau$ : the relaxation time

$k_{B}$ : the Boltzmann

$h^{2}$ : the reduced Planck constant.

The effect of changing graphene's chemical potential $\left(\mu_{c}\right)$ on the surface conductivity has been studied [34]. This effect varies depending on the carrier density, which can be 
controlled by gate voltage, electric bias field, or chemical doping. Increasing the chemical potential also causes an increase in graphene surface conductivity. In other words, this causes a shift in antenna resonances at higher frequencies. On the other hand, it allows the emergence of flexible antenna designs that can be changed by the shift in antenna resonance caused by the chemical potential change. The value in chemical potential can be controlled electrically by varying the gate voltage $\left(V_{g}\right)$. The formula explaining this situation is given below (Equation (2)). Graphene conductivity ranges are given according to the relevant frequency bands in the study of Gatte et al. [34].

$$
V_{g}=\left[\frac{q_{e} \mu_{c}^{2} h}{\pi h^{2} v_{f}^{2} \varepsilon_{0} \varepsilon_{r}}\right]
$$

Inum et al. give the real and imaginary values of the surface conductivity of graphene depending on the frequency for a changing chemical potential and a constant relaxation time at their study [33]. They show that the chemical potential and the conductivity change point are important parameters to adjust the resonance frequency.

In a study [35], the antenna produced with graphene was compared with the other antennas with different metals instead of graphene. When the results are examined, it is seen that the reflection coefficients of the metal-based antenna are less adapted than the graphene. On the other hand, graphene performs better in terms of reflection coefficient, decreasing from -6.440 to $-15.125 \mathrm{~dB}$. Graphene shows better results than metal in terms of performance with a well-adapted resonance frequency. Prasanna and Banu [36] examined the "Effect of Copper and Graphene Material Bow-tie Structured Antenna for $1.2 \mathrm{GHz}$ Application." It is seen that graphene performs better in antennas, since its conductivity is much better than copper. In addition, resistance and stub-matching problems are significantly reduced compared to copper and offer better bandwidth. All these situations suggest that using graphene is more functionally effective than copper. Considering all these parameters, graphene was used as a conductive material to produce the antenna suitable for the desired target both at an affordable cost and in the desired bandwidth, and a 3D printer was used as the production technique.

A traditional microstrip patch antenna has a high-quality factor, leading to some disadvantages related to the narrow bandwidth. Many techniques have been developed to increase the impedance bandwidth, including adopting the known stacked patches [37], parasitic resonators [38], and capacitive coupling feed [39,40]. It is still challenging to obtain a wider bandwidth, since the main solution uses a thick and/or low dielectric constant substrate.

Metamaterial-based absorbers and antennas with different fractal structures are being studied to expand the bandwidth [41,42]. While studies to increase the bandwidth of antennas are important, it is also very important that antenna production costs are affordable and easy to manufacture.

It is known that all conventional antenna manufacturing techniques have disadvantages such as high tool and equipment cost, small volume prototyping, or long lead times for production [43-46]. The new technologies used for antenna prototyping are laser micromachining and 3D printing technologies. The laser micro-processing technology is a common method that can be used to process many materials such as plastic, glass, and metal and has a versatile process to produce the desired outputs by providing thin foils. This technology includes many mechanisms such as cutting, drilling, marking, turning, and threading. The ability to drill holes at the micron level or make fine cuts is preferred in antenna production as in many areas. Apart from that, this technology presents some problems as it has a thermally induced process. For example, it causes a change in material properties in the heat-affected area, as well as causing thermal stress. In addition, they are economically very expensive and have optical problems. Therefore, laser micromachining technology was not preferred in this study.

Recently, the expansion of 3D printing offers new chances for low-cost, fast, and on-demand production of millimeter-wave, microwave, and terahertz $(\mathrm{THz})$ antennas and components [47-50]. With the rapid development of 3D-printing technology, an alternative 
solution has been provided, especially for the application of microwave antennas [51,52]. It offers higher manufacturing accuracy at a lower cost and provides great flexibility in design and production. Therefore, it has many advantages compared to the standard production methods. With 3D printing, the devices can be produced in one piece, and the performance loss caused by combining the parts can be prevented.

There are two widely used 3D-printing techniques [53-61]: polymer/dielectric and all-metal. As the working frequency band enters the millimeter/microwave range, the printed parts' quality for the resulting antenna is of great importance. The print resolution, structural limitations, and surface quality are among the many intangible factors that are hugely important for a functional antenna part. Millimeter-wave/microwaves $/ \mathrm{THz}$ antennas usually have great details in their geometry, which poses challenging fabrication methods. For all these reasons, it has become attractive to use commercial 3D printers to achieve high spatial resolution, small structure layer thickness, and low surface roughness.

Microstrip antennas have become remarkably interesting in that they can be used in many different application areas owing to their wide operating bandwidth and easy adjustment alternatives [62-66]. Due to advances in handheld electronic devices, these devices need to be thinner to improve performance in small-sized devices [67-69]. Until now, in the literature, many antenna studies with different designs - the circle [70], ellipse [71], triangle [72], fractal [73], U-shaped [74], etc. [75-77] — have been carried out to increase the bandwidth and miniaturization. The bow-tie antenna, one of the microstrip antenna types, has also been studied in many different applications.

It is well known that the bow-tie antenna designs are application-specific, and the slots are added to increase the bandwidth. Therefore, two parameters need to be well specified for better performance: the location and size of the slot. One of the contributions of this study is that the slot dimensions are chosen especially for the required bandwidth and gain.

Graphene-based antenna studies have been carried out intensively, especially for the last five years $[33,35,78-86]$. However, using graphene as an antenna is not always an easy task, and the production techniques also play an essential role in this manner. Another contribution of this study is that a standard and cheap 3D printer is used to produce the antennas. In addition, the study results can be used as a practical reference of the effect of the slot size on the antenna performance and can be considered the novelty of this study. Finally, the graphene-based patch antenna's gain is better than the copper antennas when used as the radiating element.

\section{Material and Method}

\subsection{Materials}

In this study, Esun PLA Plus Filament (Filament, esun, Shenzhen, China) was preferred for the substrate material of the antenna due to its high surface quality, high layer structure, and ten times more durability than standard PLA filaments. Detailed information on Physical and Print performances is given in Table 1.

Table 1. Physical and print performance properties of Esun PLA+ filament [87].

\begin{tabular}{cccc}
\hline \multicolumn{2}{c}{ Physical Performance Properties } & \multicolumn{2}{c}{ Print Performance Properties } \\
\hline Parameters & PLA+ & Parameters & PLA+ \\
Appearance & white & Surface finish & No obvious layering \\
Tensile strength & $63 \mathrm{Mpa}$ & Hole column fitting model & $0.3 \mathrm{~mm}$ \\
Elongation at break & $20 \%$ & Hanging model & $<60^{\circ}$ \\
Bending strength & $74 \mathrm{Mpa}$ & Suspension bridge & $50 \mathrm{~mm}$ \\
Flexural modulus & $1934 \mathrm{Mpa}$ & - & - \\
Notch impact & 9 & - & - \\
\hline
\end{tabular}


Black Magic 3D Conductive Graphene Composite filament is used for the conductive part of the antenna due to its superior conductivity and improved mechanical properties, and its detailed properties are given in Table 2.

Table 2. Properties of 3D-conductive graphene composite filament [88].

\begin{tabular}{cc}
\hline Properties & \\
\hline Brand & Black Magic 3D \\
Weight & 0.1 \\
Volume resistivity & $0.6 \mathrm{ohm}-\mathrm{cm}$ \\
Color & Black \\
Diameter & $1.75 \mathrm{~mm}$ \\
Size & $100 \mathrm{~g}$ \\
Min/max printing temperature & $220^{\circ} \mathrm{C}$ \\
Country & United States \\
\hline
\end{tabular}

The bow-tie microstrip patch antenna design procedure is given in Figure 1. Computer analysis software is central to this work for the design process, as the researcher must have the appropriate design parameters to start the production process. Simulation software is an essential tool for designing a microstrip patch antenna with bandwidth at the desired resonance frequency and showing band-pass, band-stop, or ultra-wideband characteristics. Otherwise, a new antenna must be produced for every changed parameter of the antenna, and the reflection/transmission be measured. Therefore, this process causes a loss of time and increases the design cost. For this reason, using simulation and design software to obtain the transmission/reflection characteristics and optimize the antenna parameters reduces the cost and saves time. In this study, software named CST Microwave Studio was used for microstrip patch antenna design. Polylactic Acid from Esun (Esun PLA+) with a relative dielectric constant of 2.54 and a loss tangent of 0.015 was chosen as the suitable substrate material for the designed antenna. The dielectric material thickness was determined as $1.70 \mathrm{~mm}$. Graphene PLA from BlackMagic was preferred for the conductive part, and its thickness is also $1.70 \mathrm{~mm}$. A computer code that performs the mathematical calculations of the bow-tie antenna was written using MATLAB software (2019, The Mathworks, Inc., Natick, MA, USA). According to the calculated dimensions, the design of the antenna was carried out with the CST Microwave Studio software (CST Studio Suite 2019, Dassault Systèmes, Waltham, MA, USA).

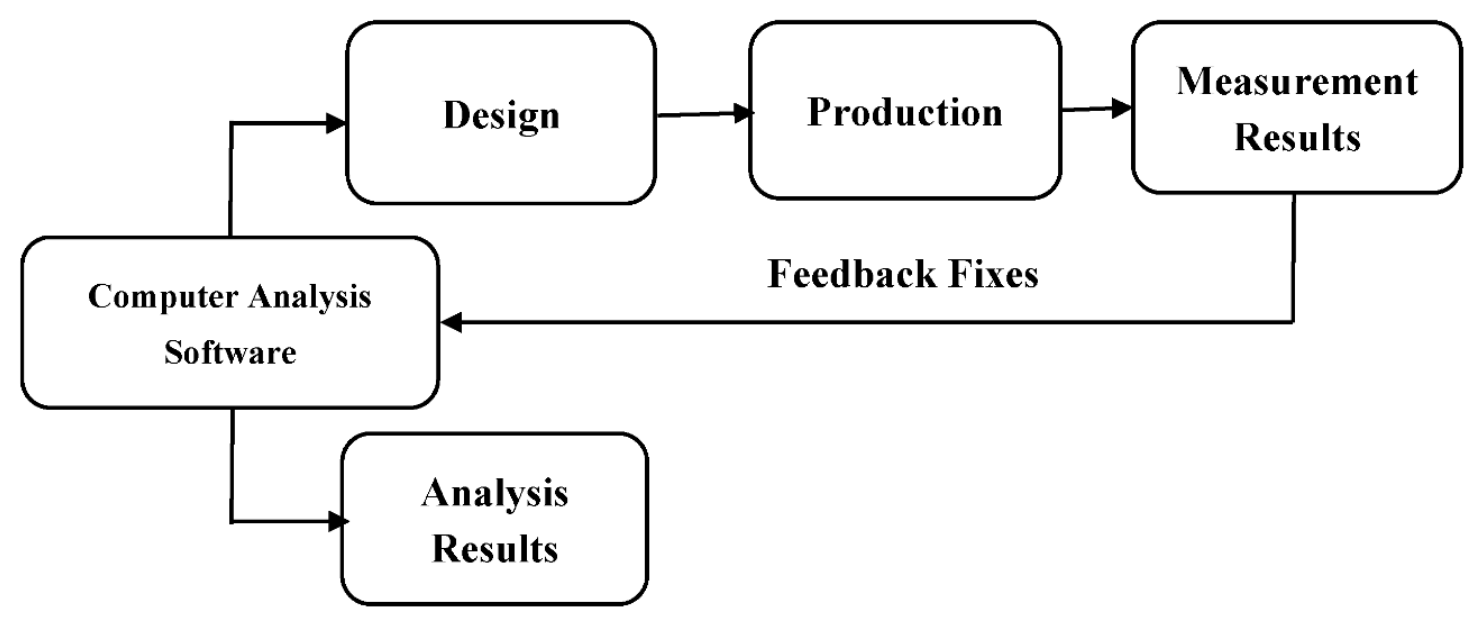

Figure 1. The design procedure of bow-tie microstrip patch antenna.

In this section, the parameters affecting the configurability of the graphene-based antenna are evaluated. The first of the two kinds of parameters are related to the geometric structure of the antenna, and it can be optimized with numerical simulations, while the 
other is related to the graphene model related to the calculation in the previous section. The study aims to understand the behavior of the graphene-based antenna and contribute to future studies of graphene-based antennas.

\subsection{Design and Production of the Bow-Tie Microstrip Antenna}

A bow-tie microstrip antenna structure is planned to improve the antenna's performance in biomedical applications. The design and simulation study of the proposed antenna is carried out in the CST Microwave Studio. The antennas are designed in Tinkercad, which is an online 3D design platform developed by Autodesk Inc. (San Rafael, CA, USA) and built with Creality Ender 3 Pro 3D printer (Creality, Shenzhen, China).

Material selection is one of the pivotal problems to be considered in the design process, as it has a significant impact on antenna performance. Polylactic Acid (PLA; $\varepsilon_{\mathrm{r}}$ $=2.54$ and $\tan \delta=0.015)$ and Acrylonitrile Butadiene Styrene (ABS) are effective on the antennas' performance. They are frequently preferred in the production of dielectric parts of antennas and microwave components. On the other hand, graphene is a suitable material for producing the conductive part of Microwave and Radio Frequency (RF) products due to its very good properties such as high charge mobility, zero bandgap, high heat conduction, high surface area, and excellent biocompatibility. Composite Conductive Graphene PLA filaments have recently been introduced, allowing graphene to be used with a 3D printer [84]. In this study, the designed antennas are produced using Conductive Graphene PLA filament for the core of the antenna and standard PLA for the dielectric substrate parts. The volume resistivity of the used graphene filament is $0.6 \Omega-\mathrm{cm}$ [89]. The product of the sheet resistance $(\Omega / \mathrm{sq})$ and the thickness of the material in centimeters is equal to the volume resistance $(\Omega-\mathrm{cm})$ [90-92], and therefore, the sheet resistance can be obtained as given in Equation (3).

$$
\begin{aligned}
& R=\text { the volume resistivity/thickness of graphene sheet } \\
& R=0.6(\Omega-\mathrm{cm}) / 0.17(\mathrm{~cm})=0.359 \Omega
\end{aligned}
$$

The radiating patch of the microstrip antenna may be square, rectangular, circular, elliptical, triangular, or any other shape [93]. Generally, triangular structures or curved structures provide better impedance matching. The size and shape of the patch are some of the most determining factors in the properties of the antenna. However, the change of shape does not bring significant changes in the radiation characteristics. The half-power beamwidth is generally 70-90 degrees, and antenna gain is 5-6 dB. By choosing the patch model and shape appropriately, a design can be made in accordance with the desired resonance frequency, pattern, impedance, and polarization. Another novelty of this work is that the slot sizes have been chosen specifically for the required bandwidth and gain. Slots are used to regulate the current path and shape the electric field. For slots, sharp points allow electric field lines to break more easily. Circular slots show an improvement in antenna performance, which is weaker than square and rectangular slots. Filtering is done for a frequency when a slot is opened in a broadband patch made for ultra-broadband. Therefore, the optimum values of the antennas, whose numerical analyses were performed by using the finite integration technique in the CST Microwave Studio simulation program, were used in the designs. In addition, the effect of slots and their different sizes on antenna performance is shown.

In this study, three different antennas, one without a slot, Figure 2, the other two with different patch sizes, Figure 3, are designed and produced. The dimensions of the antennas are given in Table 3. 


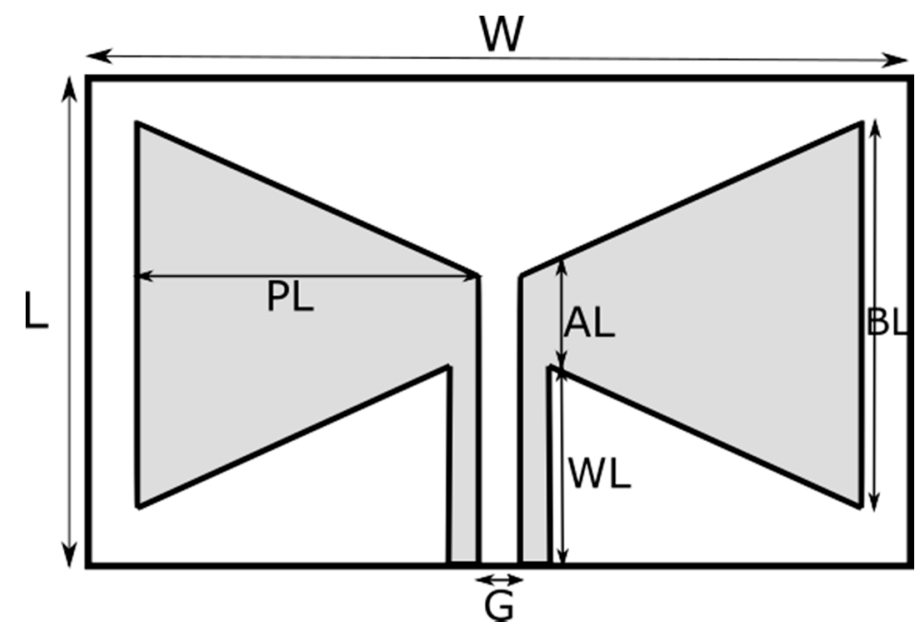

Figure 2. The design geometry of Antenna-1.

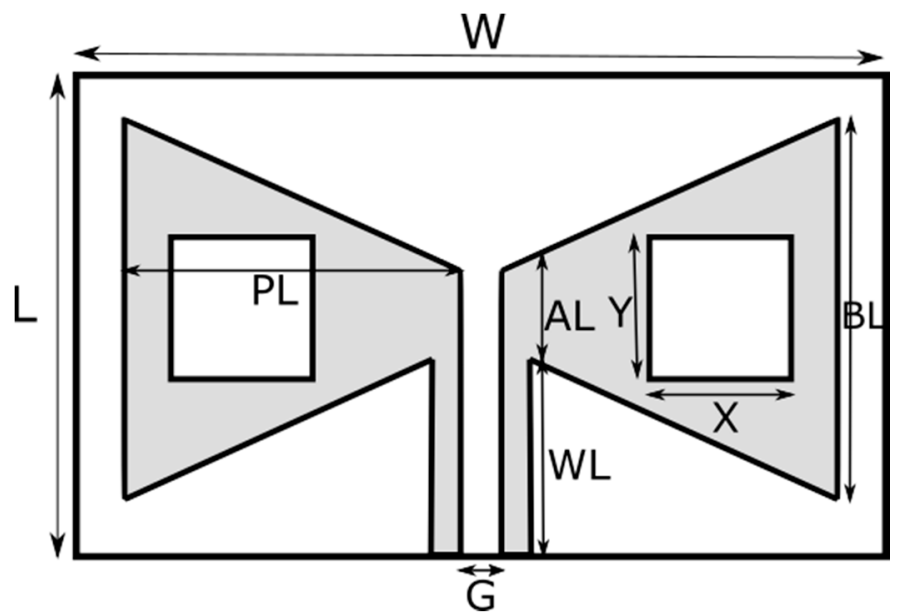

Figure 3. The design geometry of Antenna-2 and Antenna-3 with graphene substrate and different patch dimensions.

Table 3. Bow-tie Antenna-2 and Antenna-3 parameters.

\begin{tabular}{ccc}
\hline Parameters & $\begin{array}{c}\text { Dimensions } \\
\text { Antenna-2 }\end{array}$ & $\begin{array}{c}\text { Dimensions } \\
\text { Antenna-3 }\end{array}$ \\
\hline Patch length PL & $36 \mathrm{~mm}$ & $36 \mathrm{~mm}$ \\
Base length BL & $32 \mathrm{~mm}$ & $32 \mathrm{~mm}$ \\
Gap & $4 \mathrm{~mm}$ & $4 \mathrm{~mm}$ \\
Feedline width & $0.6 \mathrm{~mm}$ & $0.6 \mathrm{~mm}$ \\
Apex length AL & $5.4 \mathrm{~mm}$ & $5.4 \mathrm{~mm}$ \\
Substrate length L & $44 \mathrm{~mm}$ & $44 \mathrm{~mm}$ \\
Substrate width W & $88 \mathrm{~mm}$ & $88 \mathrm{~mm}$ \\
Aperture length for patch X & $8 \mathrm{~mm}$ & $14 \mathrm{~mm}$ \\
Aperture width for patch Y & $16 \mathrm{~mm}$ & $16 \mathrm{~mm}$ \\
\hline
\end{tabular}

The three bow-tie antennas produced for use in biomedical applications are shown in Figure 4. If it is desired to be used in more specific applications, it can be easily adjusted with antenna design changes. 


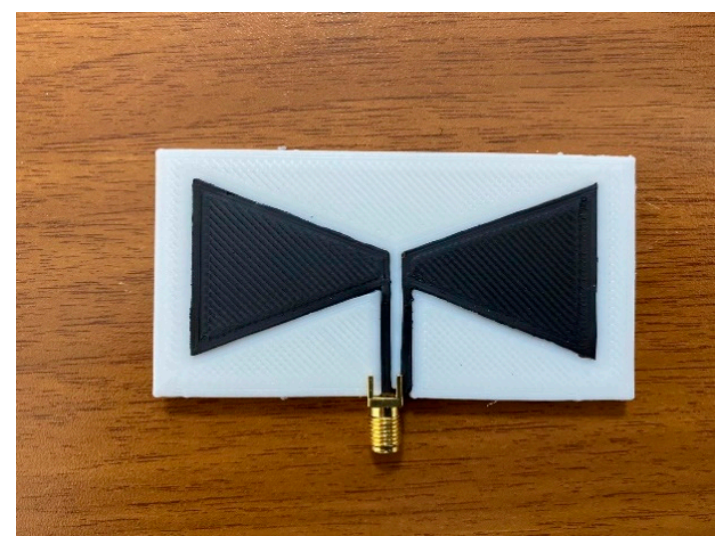

(a)

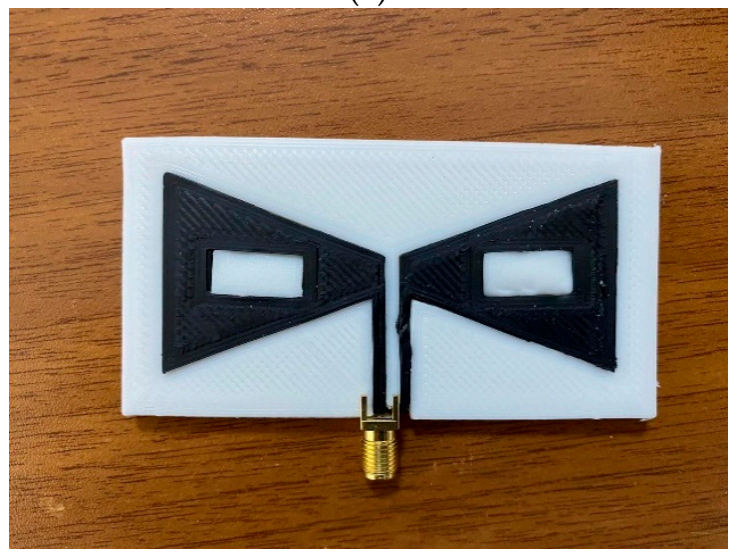

(b)

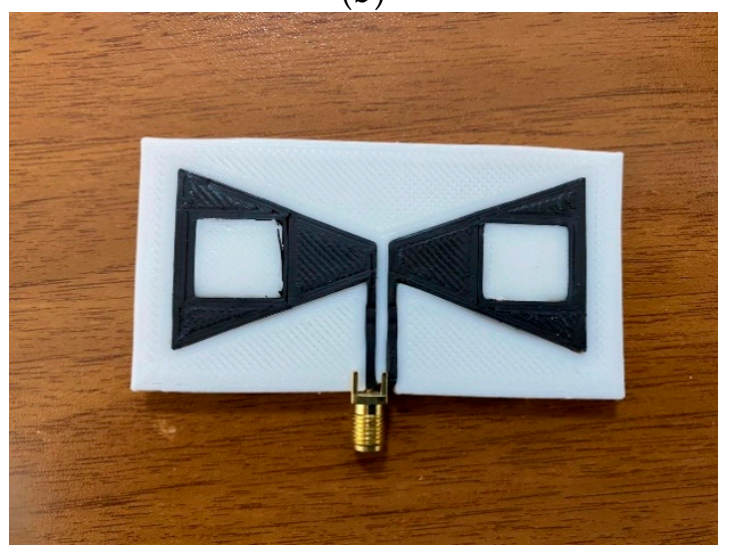

(c)

Figure 4. Fabricated bow-tie (a) Antenna-1, (b) Antenna-2, and (c) Antenna-3.

An SMA connector is connected to the antenna's terminals by heating and softening the graphene; see Figure 4. The connector's positive pin is soldered to the right triangular patch that acts as a positive terminal, and the negative pin is soldered to the left triangular patch.

The microwave antennas' design and dimensions were optimized through the simulations using the CST Microwave Studio software. The CAD design was prepared using Tinkercad, and Ultimaker Cura was used to generate gcode for the 3D printer. A commercial Creality Ender 3 Pro printer was utilized to manufacture a 3D printed substrate part from PLA and a conductor part from graphene. The bed and the nozzle temperatures were adjusted as $60{ }^{\circ} \mathrm{C}$ and $205^{\circ} \mathrm{C}$, respectively for the PLA and $50{ }^{\circ} \mathrm{C}$ and $220{ }^{\circ} \mathrm{C}$ for the graphene. An intermediate printing head speed of $50 \mathrm{~mm} / \mathrm{s}$ and $30 \mathrm{~mm} / \mathrm{s}$ was selected for PLA and graphene, respectively. A nozzle with $0.5 \mathrm{~mm}$ size is used for the printing. 
Figure 5 shows the manufacturing of the antenna with a commercial 3D printer. Antenna measurements were made in the operating frequency range of $2-20 \mathrm{GHz}$ using a PNA-L Agilent vector network analyzer. Before the measurement was carried out, the VNA was calibrated with a calibration kit with a short circuit, open circuit, and loading apparatus, respectively. After the calibration process, the produced antennas were connected to the $\mathrm{VNA}$, and the return loss parameter and gain measurement results were obtained.

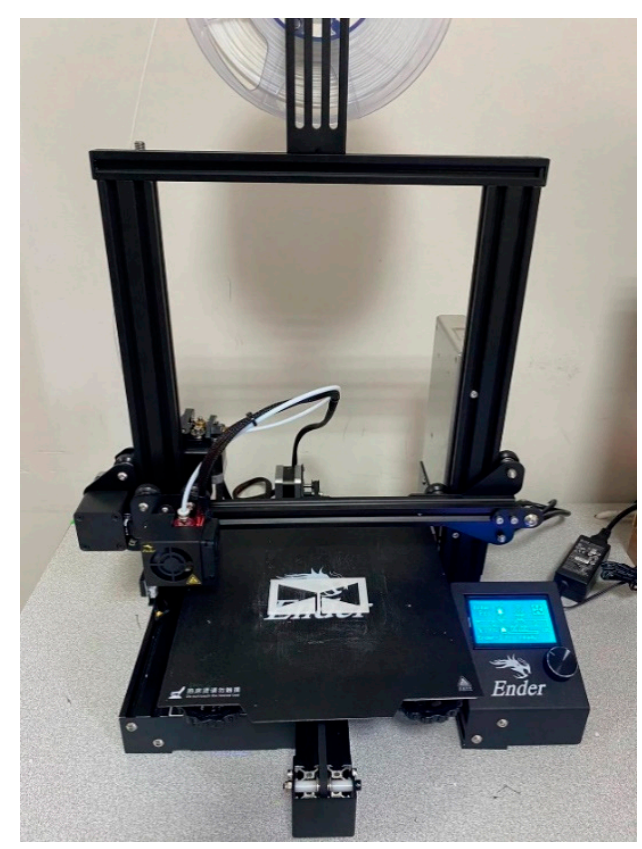

Figure 5. Creality Ender 3 Pro 3D printer.

In addition, it was also investigated how the changes to be made in antenna geometries, especially in the graphene patch part, can affect the cross-sectional absorption areas. The physical parameters for all antennas are assumed to be $T=300 \mathrm{~K}$ and $\mu_{e}=0 \mathrm{eV}$. It is seen that the antennas have resonances close to each other, and there is little difference between them, resulting from different patch structures. As shown in Figure 6, it is clear that the antenna has a large $\sigma_{a b s}$ value, especially in the patch part, which means there is no inference.

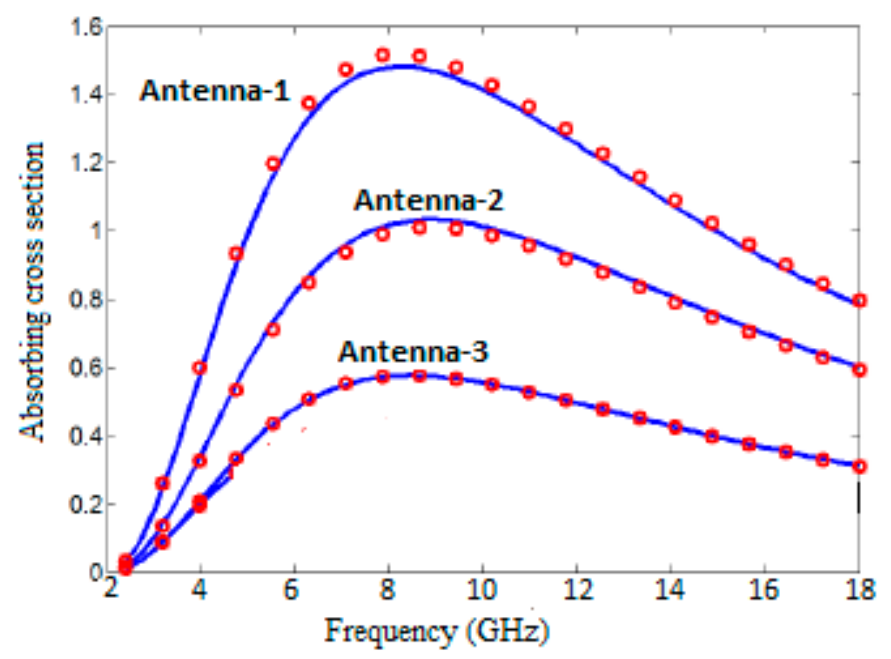

Figure 6. Absorbing cross-section in $(\mu \mathrm{m})^{2}$ of Antenna-1, Antenna-2, and Antenna-3 with $T=300 \mathrm{~K}$, $\mu_{e}=0 \mathrm{eV}$ in CST Microwave Studio. 


\section{Results and Discussion}

Before interpreting the results, the measurement device and its arrangement mentioned in the previous section are shown in Figure 7. The transient solver of the simulation program was used to obtain an accurate result, and the necessary number of network applications was provided. The return loss of the antenna was measured with the aid of a network analyzer.

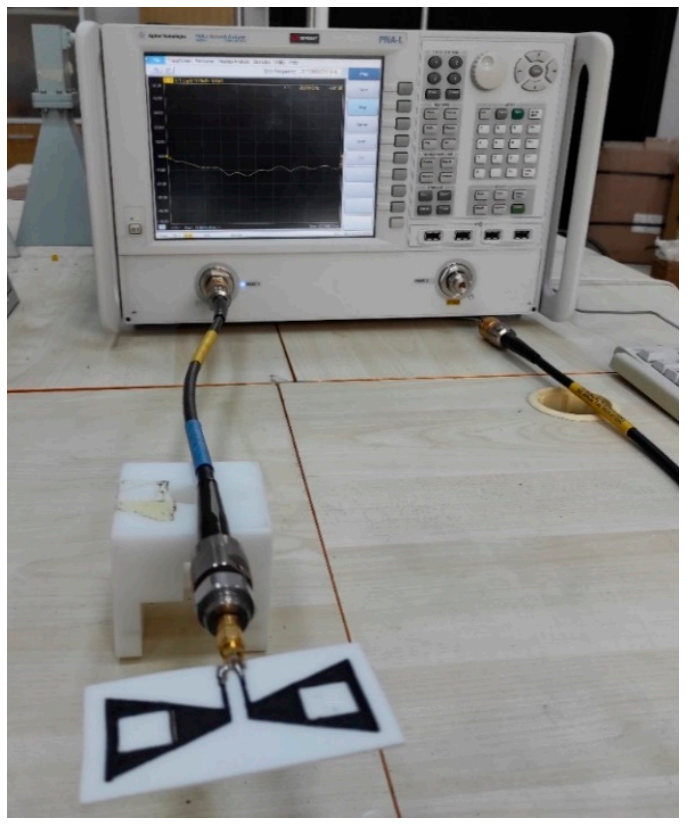

Figure 7. Measurement setup by using Keysight Technologies' PNA-L Agilent vector network analyzer.

The reflection coefficients of Antenna-1, Antenna-2, and Antenna-3 are given in Figure $8 \mathrm{a}-\mathrm{c}$, respectively, to show both the advantage of the adjustable surface conductivity of graphene and to examine its usefulness in microwave antenna designs. Analyses were carried out by applying electrical fields of $0.1,0.3,0.5$, and $0.7 \mathrm{eV}$, respectively, to the antenna created in the CST Microwave Studio software environment. These data presented in Figure 8 prove the advantages of highly variable graphene conductivity for tuning the antenna resonance frequency, which is also mentioned in the graphene material part. Accordingly, the relaxation time $(\tau)$ is accepted as $0.1 \mathrm{ps}$. When the data in the figure are examined, there is an observed improvement in harmony of the chemical potential for Antenna- 1 and the reflection coefficient, while inconsistency is observed for Antenna-2 and Antenna-3, especially at $0.7 \mathrm{eV}$.

It has been shown that the polarization and permeability of the antennas can be achieved without making any changes in the antenna dimensions or physical structure only by changing the voltage applied to the graphene layer, which changed the Fermi energy level [94-97]. Equation (1) shows that the conductivity of graphene can be adjusted dynamically by changing its chemical potential. Figure $9 \mathrm{a}-\mathrm{c}$ represent the actual and simulated values of graphene surface permeability for Antenna-1, Antenna-2, and Antenna3 , respectively, when the chemical potential is changed between 0 and $1.0 \mathrm{eV}$. 


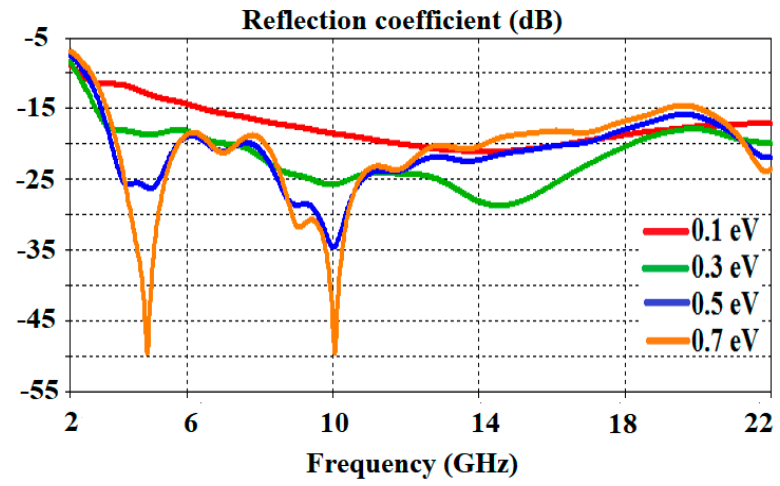

(a)

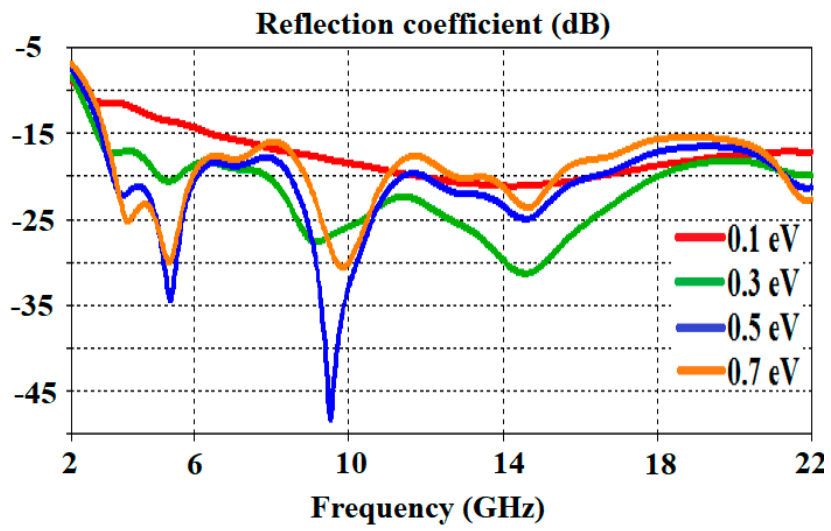

(b)

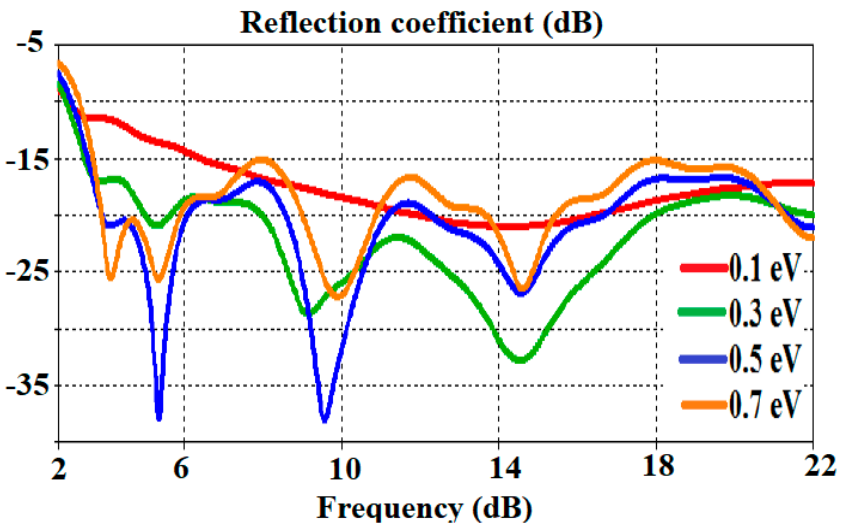

(c)

Figure 8. Reflection coefficient of (a) Antenna-1, (b) Antenna-2, and (c) Antenna-3 for varying chemical potential.

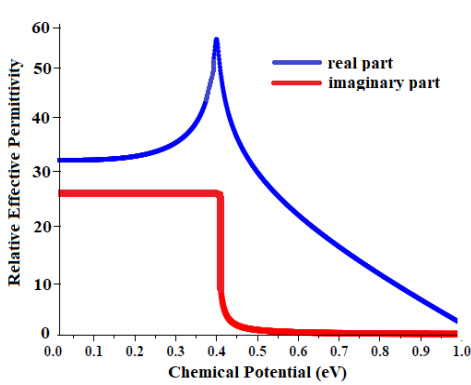

(a)

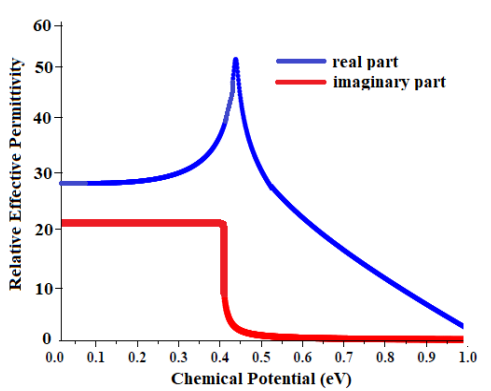

(b)

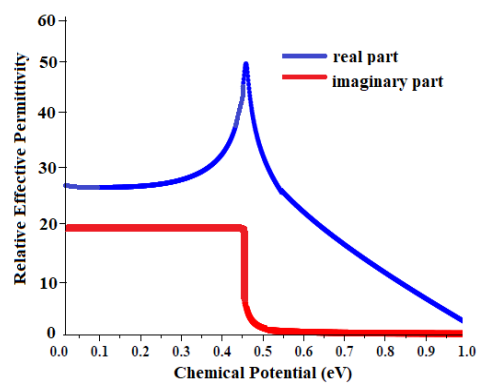

(c)

Figure 9. The real and imaginary parts of the graphene dielectric permittivity for (a) Antenna-1, (b) Antenna-2, and (c) Antenna-3 as the functions of the chemical potential. 
Figure 10 shows the bandwidth performance of the antennas in terms of return loss along with the lower $\left(f_{L}\right)$ and upper $\left(f_{H}\right)$ frequencies, where the return loss curve exceeds $-10 \mathrm{~dB}$. While it is seen that Antenna-1 provides the best performance in terms of return loss bandwidth, other antennas perform quite well in wideband ranges. In Figure 11, normalized radiation patterns were measured in both the E-plane and the H-plane, and the results were quite favorable.

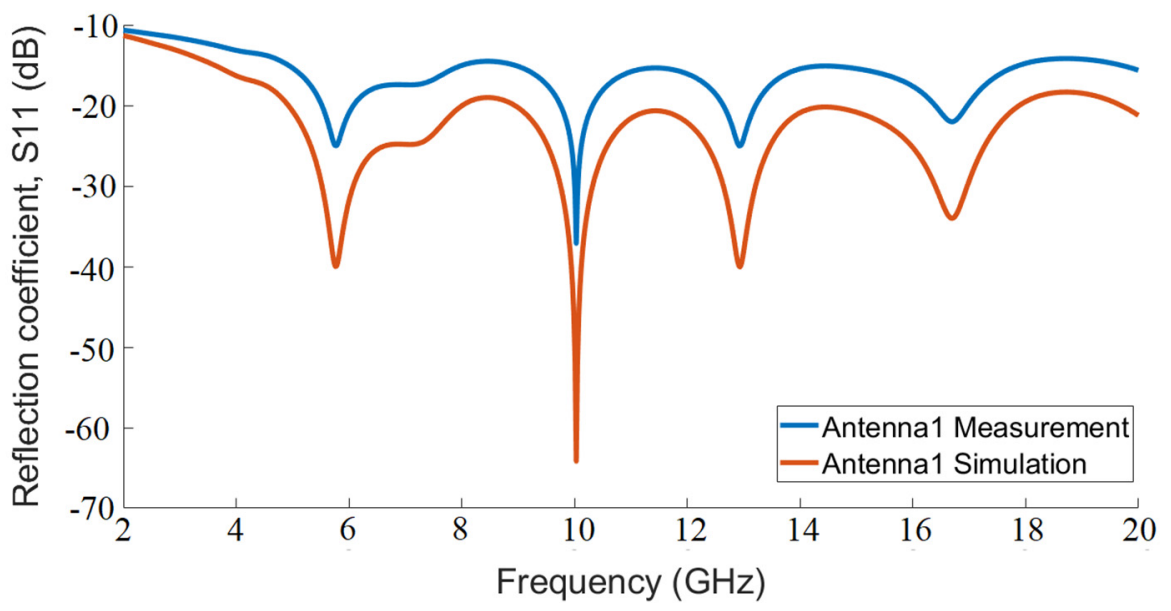

(a)

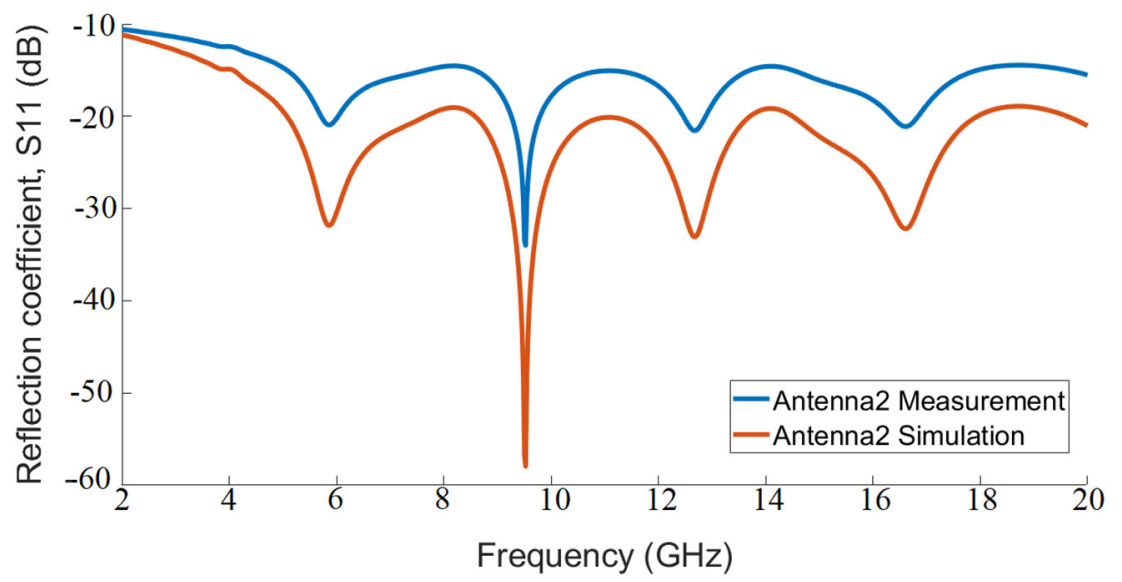

(b)

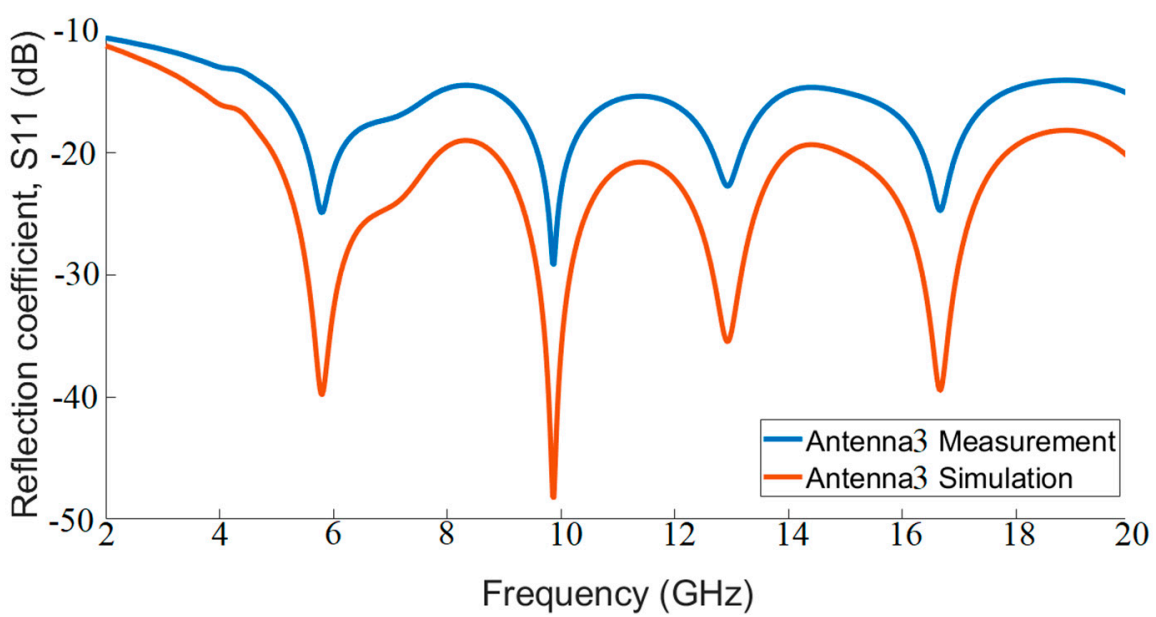

(c)

Figure 10. Reflection coefficients of (a) Antenna-1, (b) Antenna-2, and (c) Antenna-3 for bandwidth performance. 

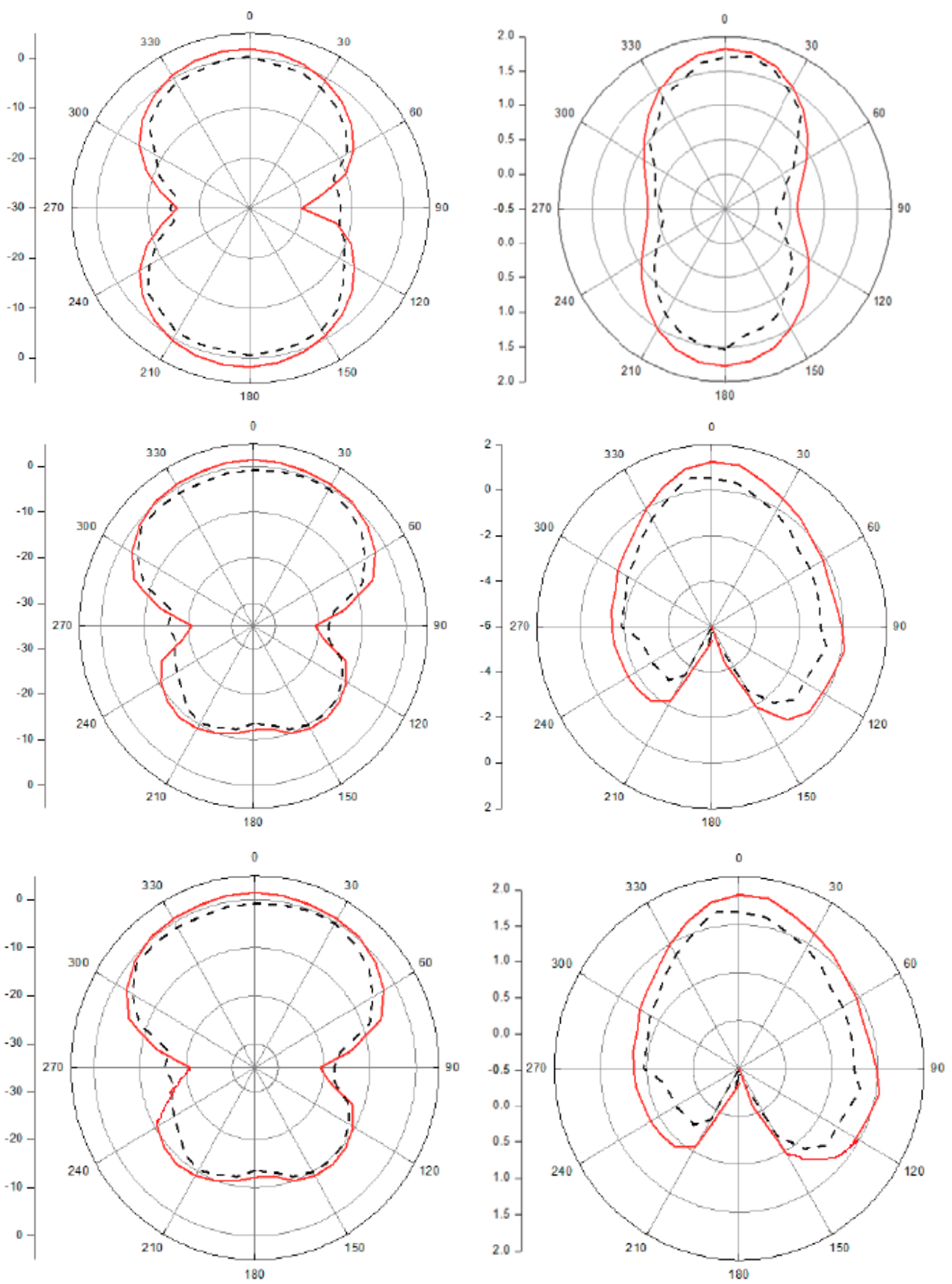

Figure 11. Radiation pattern measured (dotted-line) and simulated (straight-line) at frequency 9.5 GHz (E-plane graphics on the left side and H-plane graphics on the right side).

Although the results of the simulation and experimental studies are generally compatible, minor inconsistencies may occur. Simulation environments are ideal environments, and the values of materials used in simulation environments are average values. There are slight differences between the values of PLA and graphene material used in the simulation environment and the materials used. In addition, minor faults caused by production, such as scratches or difficulties in soldering the SMA connector, can lead to different results. Another important situation is that this study used a graphene filament for antennas instead of the raw graphene material. 
The comparison for efficiency and performance of graphene-based bow-tie antennas with previous ultra-wideband antennas are given in Table 4 . This table shows that the graphene-based bow-tie antennas designed in this study perform quite well compared to other studies in the literature. The results obtained from these three proposed antennas show that they can operate in a wide bandwidth of 2-20 GHz. It has been proven that the geometric changes made in the conductive parts of the antenna also affect their performance.

Table 4. Performance comparison of previous studies and graphene-based bow-tie antennas designed in this study.

\begin{tabular}{cccccccc}
\hline \multirow{2}{*}{$\begin{array}{c}\text { Performance } \\
\text { Parameters }\end{array}$} & \multicolumn{2}{c}{ Designed Bow-Tie Antennas } & Conventional Antennas & \multicolumn{2}{c}{ Graphene-Based Antennas } \\
\cline { 2 - 8 } & Ant.1 & Ant.2 & Ant.3 & [98] & [99] & [78] & [100] \\
\hline Return Loss (dB) & -38.85 & -34.28 & -29.95 & -32.50 & -64.00 & -25.23 & -39.92 \\
VSWR & 1.06 & 1.13 & 1.00 & 1.06 & 1.04 & NR & NR \\
Peak Gain (dBi) & 9.10 & 8.70 & 8.90 & 5.4 & 7.55 & 4.83 & NR \\
BandWidth (GHz) & 18 & 18 & 18 & 8.2 & 8.45 & 7.35 \\
\hline
\end{tabular}

In order to demonstrate the effect of graphene in one of the graphene-based antenna studies, the study was carried out by choosing copper as the conductive patch part [101]. From the study of Azizi et al., it is clear that the return loss peak value is almost twice that obtained with the copper patch (about $-29 \mathrm{~dB}$ ) for the graphene patch [101]. In another study [34], undoped pure graphene is used for the antenna design, and the antenna is modeled in the simulation. Then, different graphene models were created, and the corresponding surface conductors were obtained by applying voltage or adding chemical additives. To test and compare the graphene antenna performance, also, a traditional copper antenna design is prepared. The results showed that the graphene antenna has significant improvements in good reflection, radiation efficiency, and gain compared to the copper antenna. Furthermore, simulation studies for the Antenna-1 structure in this study were repeated for the case in which the conductive part is graphene and copper. As can be seen in Figure 12. Although the geometry is the same, it is seen that the selection in the conductive part affects the antenna performance.

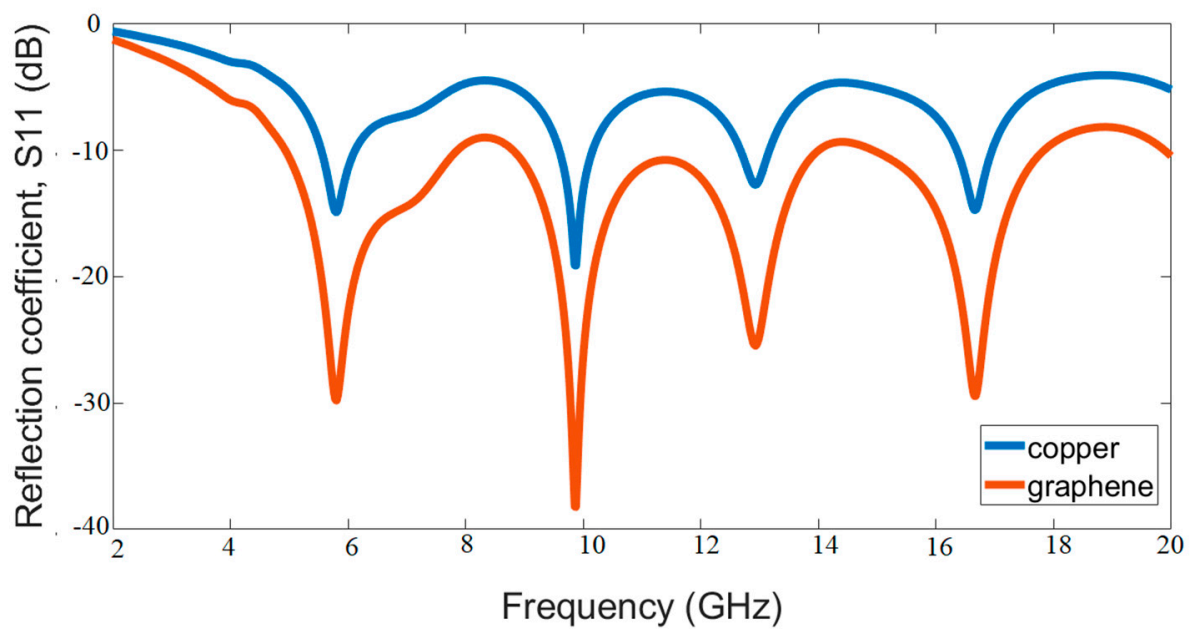

Figure 12. The simulation comparison results of the return loss $\left(S_{11}\right)$ of the graphene-based antenna and copper-based antenna for Antenna-1 in this study.

Additionally, the comparison of the antenna produced in this article with the previously studied antennas is given in Table 5. 
Table 5. Comparison of the manufactured antenna with some studies.

\begin{tabular}{|c|c|c|c|c|c|c|}
\hline $\begin{array}{l}\text { Reference } \\
\text { No. }\end{array}$ & $\begin{array}{l}\text { Antenna } \\
\text { Type }\end{array}$ & $\begin{array}{l}\text { Dimensions } \mathrm{mm}^{3} \\
\text { and Applications }\end{array}$ & $\begin{array}{l}\text { Substrate, } \\
\text { Conductive } \\
\text { Element }\end{array}$ & $\begin{array}{l}\text { Bandwidth } \\
\text { (FBW\%) }\end{array}$ & $\begin{array}{l}\text { Resonant } \\
\text { Frequency }\end{array}$ & $\begin{array}{l}\text { Antenna Gain } \\
\text { and Efficiency }\end{array}$ \\
\hline [102] & $\begin{array}{l}\text { Elliptical } \\
\text { quasi-dipole } \\
\text { antenna }\end{array}$ & $\begin{array}{l}46 \times 45 \mathrm{~mm}^{2}, 2 \text { up } \\
\text { to } 5 \mathrm{GHz} \text { for } \\
\text { low-cost wireless } \\
\text { communications } \\
\text { applications. }\end{array}$ & $\begin{array}{c}\text { Kapton } \\
\text { Polyimide, } \\
\text { graphene flakes }\end{array}$ & $1-5 \mathrm{GHz}$ & $2 \mathrm{GHz}$ & $\begin{array}{l}2.3 \mathrm{dBi} \text { at } \\
4.8 \mathrm{GHz} \\
56 \pm 5 \%\end{array}$ \\
\hline [103] & $\begin{array}{c}\text { CPW-fed } \\
\text { H-shaped slot } \\
\text { antenna }\end{array}$ & $\begin{array}{c}32 \times 52 \times 0.28 \\
\text { UWB antenna for } \\
\text { wearable } \\
\text { applications }\end{array}$ & $\begin{array}{l}\text { Flexible ceramic } \\
\text { substrate, } \\
\text { graphene } \\
\text { assembled film } \\
\text { (GAF) }\end{array}$ & 4.1-8.0 GHz & $\begin{array}{c}4.45,5.6, \text { and } \\
7.1 \mathrm{GHz}\end{array}$ & $\begin{array}{l}3.9 \mathrm{dBi} \text { at } \\
7.45 \mathrm{GHz}\end{array}$ \\
\hline [104] & $\begin{array}{l}\text { CPW-fed } \\
\text { rectangular } \\
\text { slot with } \\
\text { chamfer }\end{array}$ & $\begin{array}{l}11.8 \times 12.2 \times 0.1 \\
\text { Mobile terminal for } \\
\text { fifth generation } \\
(5 \mathrm{G})\end{array}$ & $\begin{array}{c}\text { Kapton } \\
\text { polyimide, } \\
\text { Graphene ink }\end{array}$ & $14.30-15.71 \mathrm{GHz}$ & $13.8 \mathrm{GHz}$ & $9.28 \mathrm{dBi}, 67.44 \%$ \\
\hline [105] & $\begin{array}{l}\text { Bow-tie } \\
\text { antenna }\end{array}$ & $\begin{array}{l}\text { Optical near-field } \\
\text { enhancement }\end{array}$ & Glass graphene & $14.3-35.3 \mathrm{THz}$ & - & - \\
\hline This study & $\begin{array}{l}\text { Bow-tie } \\
\text { antenna }\end{array}$ & $\begin{array}{l}44 \times 88 \text { (outer size), } \\
\text { ultra-wideband } \\
\text { applications for } \\
\text { especially medical } \\
\text { applications }\end{array}$ & $\begin{array}{l}\text { PLA, graphene } \\
\text { filament }\end{array}$ & $2-20 \mathrm{GHz}$ & $\begin{array}{c}\text { Antenna-1 } \\
10.01 \mathrm{GHz} \text {, } \\
\text { Antenna-2 } \\
9.6 \mathrm{GHz} \text {, } \\
\text { Antenna-3 } \\
9.8 \mathrm{GHz}\end{array}$ & $\begin{array}{l}\text { Antenna-1 } \\
9.10 \mathrm{dBi}, \\
\text { Antenna-2 } \\
8.70 \mathrm{dBi}, \\
\text { Antenna-3 } \\
8.90 \mathrm{dBi}\end{array}$ \\
\hline
\end{tabular}

Graphene is preferred in antennas due to its many important potentials, such as reducing antenna sizes, providing good integration with electronic circuits, dynamic adjustment possibility, transparency, and flexibility [106]. The most important feature of graphene that makes it usable in antenna applications is the conductivity tensor in its structure $[107,108]$. The conductivity tensor depends on many parameters such as temperature, scattering rate, Fermi energy, and electron velocity. The conductivity tensor can be controlled when interacting with static electricity, and magnetic fields from the outside provide a dynamic structure for products made of graphene. Another important feature is that it is frequencydependent. As the applied electric field increases, the conductivity values increase, but when the frequency rises above $103 \mathrm{GHz}$ in the same electric field, it quickly decreases to zero [109]. Therefore, their conductivity changes according to frequency ranges. Since the frequency range used in this study is between 2 and $20 \mathrm{GHz}$, graphene is a good conductor in this range. Although copper offers better properties for antenna production, the fact that graphene and PLA can be used with a 3D printer provides a very good advantage in terms of production.

Gómez-Díaz and Perruisseau-Carrier carried out the first graphene-based patch antenna in their study [110]. They produced the antenna patch part from high-rate graphene. The return loss and radiation efficiency of the antenna were investigated, and it was observed that the efficiency decreased due to losses in graphene. Another important inference is that regardless of the externally applied electric field, it does not significantly change the resonance frequency of the patch. Therefore, there is no need to go through reconfiguration while antenna efficiency can be controlled.

In another study, an antenna with a diaphragm connection was produced to be used in the band from 14 to $16 \mathrm{GHz}$ [109]. In this study, the patch is made of copper, and the surface resistance is $100 \Omega$. This property corresponds to the case where $\tau=0.5 \mathrm{ps}$ and $\mu_{c}=0.175 \mathrm{eV}$ in graphene. In the simulation study where graphene is applied, the return loss is quite good, while the radiation efficiency and radiation power are lower than the metal patch and no-patch conditions. To summarize, it is not very useful to use 
graphene to reduce the size of the antennas or change their geometry, but it is seen that it is mechanically flexible, has optical transparency, is easy to produce with a 3D printer, and even creating a conductive patch with graphene and metal mixture provides better performance. It is known that these examples are valid for simple monoatomic graphene layers, but this situation changes in multi-layer graphene applications with an increase in radiation efficiency [109].

\section{Conclusions}

In summary, three different bow-tie microstrip antennas that can operate in the $2-20 \mathrm{GHz}$ range for ultra-wideband applications have been designed and experimentally implemented. Numerical analyses were made using the finite integration technique in the CST Microwave Studio simulation program. The designed antennas were selected from the non-slot state, and the radiating part was selected with two different slot sizes and produced from graphene filament. The substrate is produced from PLA material. It has been observed that all three designs perform quite well in ultra-wideband applications. The effect of design differences in antennas is reflected in antenna return losses. Especially for Antenna-1, the return loss seems to be quite good. In addition, copper is generally used for the radiating part in classical methods. This study has also shown that graphene performs better than copper because it is a good conductor, contrary to classical methods.

Another critical point is that the production of 3D-printer technology is one of the new aspects of the proposed study, as it is cost-effective and easy to produce, unlike classical production methods. In addition, the voltages applied to graphene changes the chemical potential and cause changes in the permittivity of graphene. In this respect, it has been a critical study to provide the opportunity to create different frequency ranges. It is considered to use one or more of these produced antennas for biomedical UWB applications for future studies.

Funding: This research received no external funding.

Institutional Review Board Statement: Not applicable.

Informed Consent Statement: Not applicable.

Acknowledgments: We would like to thank İskenderun Teknik University Engineering Faculty Electrical and Electronics Engineering Department for their support in the measurements.

Conflicts of Interest: There is no conflict of interest.

\section{References}

1. Pozar, D.M. Microstrip antennas. Proc. IEEE 2017, 80, 79-91. [CrossRef]

2. Balanis, C.A. Antenna Theory: Analysis and Design, 3rd ed.; John Wiley \& Sons: Hoboken, NJ, USA, 2005.

3. Yang, Z; Browning, K.C.; Warnick, K.F. High-Efficiency Stacked Shorted Annular Patch Antenna Feed for Ku-Band Satellite Communications. IEEE Trans. Antennas Propag. 2016, 64, 2568-2572. [CrossRef]

4. Chang, E.; Long, S.; Richards, W. An experimental investigation of electrically thick rectangular microstrip antennas. IRE Trans. Antennas Propag. 1986, 34, 767-772. [CrossRef]

5. Hall, P. Probe compensation in thick microstrip patches. Electron. Lett. 1987, 23, 606-607. [CrossRef]

6. Kovitz, J.M.; Rahmat-Samii, Y. Using Thick Substrates and Capacitive Probe Compensation to Enhance the Bandwidth of Traditional CP Patch Antennas. IEEE Trans. Antennas Propag. 2014, 62, 4970-4979. [CrossRef]

7. Nasimuddin, K.P.E.; Verma, A.K. Wideband circularly polarized stacked microstrip antennas. IEEE Antennas Wirel. Propag Lett. 2007, 6, 21-24. [CrossRef]

8. Liu, N.-W.; Zhu, L.; Choi, W.-W.; Zhang, X. A Low-Profile Aperture-Coupled Microstrip Antenna with Enhanced Bandwidth under Dual Resonance. IEEE Trans. Antennas Propag. 2017, 65, 1055-1062. [CrossRef]

9. Pues, H.F.; de Capelle, A.R. Van An impedance-matching technique for increasing the bandwidth of microstrip antennas. IEEE Trans. Antennas Propag. 1989, 37, 1345-1354. [CrossRef]

10. Motevasselian, A.; Whittow, W.G. Miniaturization of a circular patch microstrip antenna using an arc projection. IEEE Antennas Wirel. Propag. Lett. 2017, 16, 517-520. [CrossRef]

11. Pinhas, S.; Shtrikman, S. Comparison between computed and measured bandwidth of quarter-wave microstrip radiators. IEEE Trans. Antennas Propag. 1988, 36, 1615-1616. [CrossRef]

12. Waterhouse, R. Small microstrip patch antenna. Electron. Lett. 1995, 31, 604-605. [CrossRef] 
13. Wong, H.; Lau, P.-Y.; Mak, K.-M.; Luk, K.-M. Small circularly polarised folded patch antenna. Electron. Lett. 2005, 41, 1363-1365. [CrossRef]

14. Lee, B.; Harackiewicz, F. Miniature microstrip antenna with a partially filled high-permittivity substrate. IEEE Trans. Antennas Propag. 2002, 50, 1160-1162. [CrossRef]

15. Lee, K.; Guo, Y.; Hawkins, J.; Chair, R.; Luk, K. Theory and experiment on microstrip patch antennas with shorting walls. IEE Proc.-Microw. Antennas Propag. 2000, 147, 521-525. [CrossRef]

16. Kuila, T.; Bose, S.; Mishra, A.K.; Khanra, P.; Kim, N.H.; Lee, J.H. Chemical functionalization of graphene and its applications. Prog. Mater. Sci. 2012, 57, 1061-1105. [CrossRef]

17. Avouris, P.; Dimitrakopoulos, C. Graphene: Synthesis and applications. Mater. Today 2012, 15, 86-97. [CrossRef]

18. Hussain, A.; Mehdi, S.M.; Abbas, N.; Hussain, M.; Naqvi, R.A. Synthesis of graphene from solid carbon sources: A focused review. Mater. Chem. Phys. 2020, 248, 122924. [CrossRef]

19. Jang, S.; Hwang, E.; Lee, J.H.; Park, H.S.; Cho, J.H. Graphene-Graphene Oxide Floating Gate Transistor Memory. Small 2015, 11, 311-318. [CrossRef] [PubMed]

20. Dong, Y.; Liu, P.; Yu, D.; Li, G.; Tao, F. Dual-Band Reconfigurable Terahertz Patch Antenna with Graphene-Stack-Based Backing Cavity. IEEE Antennas Wirel. Propag. Lett. 2016, 15, 1541-1544. [CrossRef]

21. Cai, Y.; Guo, Y.J.; Qin, P.; Weily, A.R. Frequency reconfigurable quasi-Yagi dipole antenna. IEEE Antennas Wirel. Propag. Lett. 2010, 9, 883-886. [CrossRef]

22. Piazza, D.; Mookiah, P.; Michele, D.; Dandekar, K.R. Pattern and polarization reconfigurable circular patch for MIMO systems. In Proceedings of the 2009 3rd European Conference on Antennas and Propagation, Berlin, Germany, 23-27 March 2009; pp. 1047-1051.

23. Li, F.; Chen, H.; Zhou, Y.; You, J.; Panoiu, N.C.; Zhou, P.; Deng, L. Generation and Focusing of Orbital Angular Momentum Based on Polarized Reflectarray at Microwave Frequency. IEEE Trans. Microw. Theory Tech. 2021, 69, 1829-1837. [CrossRef]

24. Huang, Y.; Wu, L.-S.; Tang, M.; Mao, J. Design of a Beam Reconfigurable THz Antenna with Graphene-Based Switchable High-Impedance Surface. IEEE Trans. Nanotechnol. 2012, 11, 836-842. [CrossRef]

25. Falkovsky, L.A. Optical properties of graphene. J. Phys. Conf. Ser. 2008, 129, 012004. [CrossRef]

26. Loh, K.; Bao, Q.; Eda, G.; Chhowalla, M. Graphene oxide as a chemically tunable platform for optical applications. Nat. Chem. 2010, 2, 1015-1024. [CrossRef] [PubMed]

27. Castro Neto, A.H.; Guinea, F.; Peres, N.M.R.; Novoselov, K.S.; Geim, A.K. The electronic properties of graphene. Rev. Mod. Phys. 2009, 81, 109-162. [CrossRef]

28. Ajlani, H.; Azizi, M.K.; Gharsallah, A.; Oueslati, M. Graphene-GaAs-graphene stacked layers for the improvement of the transmission at the wavelength of $1.55 \mu \mathrm{m}$. Opt. Mater. 2016, 57, 120-124. [CrossRef]

29. Ajlani, H.; Azizi, M.K.; Gharsallah, A.; Meftah, A.; Oueslati, M. Graphene-based reconfigurable transmission filter near the wavelength of $1.55 \mu \mathrm{m}$. Opt. Mater. 2017, 66, 201-206. [CrossRef]

30. Zhang, J.; Wang, G.; Zhang, B.; He, T.; He, Y.; Shen, J. Photo-excited broadband tunable terahertz metamaterial absorber. Opt. Mater. 2016, 54, 32-36. [CrossRef]

31. Seyedsharbaty, M.M.; Sadeghzadeh, R.A. Antenna gain enhancement by using metamaterial radome at THz band with reconfigurable characteristics based on graphene load. Opt. Quantum Electron. 2017, 49, 221. [CrossRef]

32. Zarrabi, F.B.; Seyedsharbaty, M.M.; Ahmed, Z.; Arezoomand, A.S.; Heydari, S. Wide band yagi antenna for terahertz application with graphene control. Optik 2017, 140, 866-872. [CrossRef]

33. Inum, R.; Rana, M.; Shushama, K.N. Development of Graphene Based Tapered Slot Antennas for Ultra-Wideband Applicatıons. Prog. Electromagn. Res. C 2017, 79, 241-255. [CrossRef]

34. Gatte, M.T.; Soh, P.J.; Rahim, H.A.; Ahmad, R.; Malek, F. The Performance Improvement of Thz Antenna Via Modelıng and Characterization of Doped Graphene. Prog. Electromagn. Res. M 2016, 49, 21-31. [CrossRef]

35. Ben Krid, H.; Houaneb, Z.; Zairi, H. Reconfigurable Graphene Annular Rıng Antenna for Medical and Imagıng Applicatıons. Prog. Electromagn. Res. M 2020, 89, 53-62. [CrossRef]

36. Prasanna, R.; Banu, N.M. Effect of Copper and Graphene Material on Bow-tie Structured Antenna for $1.2 \mathrm{GHz}$ Application. Radioelectron. Commun. Syst. 2019, 62, 189-194. [CrossRef]

37. Hu, J.; Hao, Z.-C.; Hong, W. Design of a Wideband Quad-Polarization Reconfigurable Patch Antenna Array Using a Stacked Structure. IEEE Trans. Antennas Propag. 2017, 65, 3014-3023. [CrossRef]

38. Wi, S.-H.; Lee, Y.-S.; Yook, J.-G. Wideband Microstrip Patch Antenna with U-Shaped Parasitic Elements. IEEE Trans. Antennas Propag. 2007, 55, 1196-1199. [CrossRef]

39. Yoshida, S.; Gupta, K.C.; Benalla, A.; House, A.; Talty, T.; Lee, K.F.; Aikawa, M.; Egashira, S.; Nishiyama, E.; Sipus, Z.; et al. A Wideband L-Probes Fed Circularly-Polarized Reconfigurable Microstrip Patch Antenna. IEEE Trans. Antennas Propag. 2008, 56, 581-584.

40. Antenna, P.M. A Broadband Impedance Matching Method for proximity-coupled microstrip antenna. IEEE Trans. Antennas Propag. 2010, 58, 1392-1397.

41. Bilal, R.M.H.; Rahim, A.A.; Maab, H.; Ali, M.M. Modified Wang Shaped Ultra-Wideband (UWB) Fractal Patch Antenna for Millimetre-Wave Applications. In Proceedings of the 2018 Progress in Electromagnetics Research Symposium (PIERS-Toyama), Toyama, Japan, 1-4 August 2018. [CrossRef] 
42. Bilal, R.M.H.; Saeed, M.A.; Choudhury, P.K.; Baqir, M.A.; Kamal, W.; Ali, M.M.; Rahim, A.A. Elliptical metallic rings-shaped fractal metamaterial absorber in the visible regime. Sci. Rep. 2020, 10, 14035. [CrossRef]

43. Auyeung, R.C.Y.; Nurnberger, M.W.; Wendland, D.J.; Pique, A.; Arnold, C.; Abbott, A.R.; Schuette, L.C. Laser fabrication of GPS conformal antennas. Lasers Appl. Sci. Eng. 2004, 5339, 292-297. [CrossRef]

44. Conneely, A.J.; O'Connor, G.M.; John, M.; Ammann, M.J.; Molloy, D.; Lotya, M.; Finn, D. Laser micromachining of contactless RF antenna modules for payment cards and wearable objects. Int. Congr. Appl. Lasers Electro-Opt. 2016, 2016, M501. [CrossRef]

45. Kumar, A. Challenges and Issues in the Design of Micro-machined Antennas-A Review. Recent Adv. Electr. Electron. Eng. Formerly Recent Patents Electr. Electron. Eng. 2021, 14, 75-89. [CrossRef]

46. Bhattacharyya, B.; Doloi, B. Modern Machining Technology: Advanced, Hybrid, Micro Machining and Super Finishing Technology, 1st ed.; Academic Press: Cambridge, MA, USA, 2019.

47. Nayeri, P.; Liang, M.; Austreberto Sabory-Garcı'a, R.; Tuo, M.; Yang, F.; Gehm, M.; Xin, H.; Elsherbeni, A.Z. 3D printed dielectric reflectarrays: Low-cost high-gain antennas at sub-millimeterwaves. IEEE Trans. Antennas Propag. 2014, 62, 2000-2008. [CrossRef]

48. Wu, Z.; Liang, M.; Ng, W.R.; Gehm, M.; Xin, H. Terahertz horn antenna based on hollow-core electromagnetic crystal (EMXT) structure. IEEE Trans. Antennas Propag. 2012, 60, 5557-5563. [CrossRef]

49. Yi, H.; Qu, S.W.; Ng, K.B.; Chan, C.H.; Bai, X. 3-D printed millimeterwave and terahertz lenses with fixed and frequency scanned beam. IEEE Trans. Antennas Propag. 2016, 64, 442-449. [CrossRef]

50. Zhang, B.; Zhan, Z.; Cao, Y.; Gulan, H.; Linner, P.; Sun, J.; Zwick, T.; Zirath, H. Metallic 3-D printed antennas for millimeter- and submillimeter wave applications. IEEE Trans. Terahertz Sci. Technol. 2016, 6, 592-600. [CrossRef]

51. Huang, G.-L.; Zhou, S.-G.; Chio, T.-H.; Yeo, T.S. Fabrication of a High-Efficiency Waveguide Antenna Array via Direct Metal Laser Sintering. IEEE Antennas Wirel. Propag. Lett. 2016, 15, 622-625. [CrossRef]

52. Huang, G.-L.; Zhou, S.-G.; Chio, T.-H. Highly-Efficient Self-Compact Monopulse Antenna System with Integrated Comparator Network for RF Industrial Applications. IEEE Trans. Ind. Electron. 2016, 64, 674-681. [CrossRef]

53. Zhu, Y.-J.; Li, J.; Zhang, X.; Yuan, T.; Zhong, Z.-P.; Tan, T.-Y.; Bi, X.-K. A 3-D Printed Spherical Antenna with Bandwidth Enhancement under Operation of Dual Resonance. IEEE Access 2020, 8, 19345-19352. [CrossRef]

54. Wahyudi, A.H.; Sumantyo, J.T.S.; Wijaya, S.; Munir, A. PLA-based 3D printed circularly polarized X-band horn array antenna for CP-SAR sensor. In Proceedings of the 2018 International Workshop on Antenna Technology (iWAT), Nanjing, China, 5-7 March 2018; pp. 1-4.

55. Muntoni, G.; Montisci, G.; Casula, G.A.; Chietera, F.P.; Michel, A.; Colella, R.; Catarinucci, L.; Mazzarella, G. A Curved 3-D Printed Microstrip Patch Antenna Layout for Bandwidth Enhancement and Size Reduction. IEEE Antennas Wirel. Propag. Lett. 2020, 19, 1118-1122. [CrossRef]

56. Lomakin, K.; Sippel, M.; Ullmann, I.; Helmreich, K.; Gold, G. 3D Printed Helix Antenna for 77 GHz. In Proceedings of the 2020 14th European Conference on Antennas and Propagation (EuCAP), Copenhagen, Denmark, 15-20 March 2020.

57. Sarjoghian, S.; Alfadhl, Y.; Chen, X.; Parini, C.G. A 3-D-Printed High-Dielectric Materials-Filled Pyramidal Double-Ridged Horn Antenna for Abdominal Fat Measurement System. IEEE Trans. Antennas Propag. 2021, 69, 64-73. [CrossRef]

58. Raniszewski, A.; Slojewska, B.; Piasecki, P.; Strycharz, J. Miniaturized 3D-printed Antenna Realizations for Cylindrical Surface Mounting. In Proceedings of the 2020 23rd International Microwave and Radar Conference (MIKON), Warsaw, Poland, 5-7 October 2020.

59. Njogu, P.; Sanz-Izquierdo, B.; Elibiary, A.; Jun, S.Y.; Chen, Z.; Bird, D. 3D Printed Fingernail Antennas for 5G Applications. IEEE Access 2020, 8, 228711-228719. [CrossRef]

60. Mitra, D.; Striker, R.; Cleveland, J.; Braaten, B.D.; Kabir, K.S.; Aqueeb, A.; Burczek, E.; Roy, S.; Ye, S. A 3D Printed Microstrip Patch Antenna using Electrifi Filament for In-Space Manufacturing. In Proceedings of the 2021 United States National Committee of URSI National Radio Science Meeting (USNC-URSI NRSM), Boulder, CO, USA, 4-9 January 2021.

61. Belen, A.; Güneş, F.; Mahouti, P.; Palandöken, M. A novel design of high performance multilayered cylindrical dielectric lens antenna using 3D printing technology. Int. J. RF Microw. Comput.-Aided Eng. 2020, 30, e21988. [CrossRef]

62. Chen, W.L.; Wang, G.M.; Zhang, C.X. Bandwidth enhancement of a microstrip-line-fed printed wide-slot antenna with a fractal-shaped slot. IEEE Trans. Antennas Propag. 2009, 57, 2176-2179. [CrossRef]

63. See, C.H.; Abd-Alhameed, R.A.; Zhou, D.; Lee, T.H.; Excell, P.S.A. Crescent-Shaped Multiband Planar Monopole Antenna for MobileWireless Applications. IEEE Antennas Wirel. Propag. Lett. 2010, 9, 152-155. [CrossRef]

64. Eskandari, H.; Booket, M.R.; Kamyab, M.; Veysi, M. Investigations on a Class of Wideband Printed Slot Antenna. IEEE Antennas Wirel. Propag. Lett. 2010, 9, 1221-1224. [CrossRef]

65. Gosalvitr, J.; Mahatthanajatuphat, C.; Akkaraekthalin, P.; Chaimool, S. CPW-fed slot antenna with fractal tuning stub for wideband circular polarization. In Proceedings of the 8th Electrical Engineering/Electronics, Computer, Telecommunications and Information Technology (ECTI) Association of Thailand-Conference 2011, Khon Kaen, Thailand, 17-19 May 2011 ; pp. $212-215$.

66. Song, K.; Yin, Y.-Z.; Chen, B.; Fan, S.-T.; Gao, F. Bandwidth Enhancement Design of Compact Uwb Step-Slot Antenna With Rotated Patch. Prog. Electromagn. Res. Lett. 2011, 22, 39-45. [CrossRef]

67. Tze-Hsuan, C.; Jean-Fu, K. Compact Multi-Band H-Shaped Slot Antenna. IEEE Trans. Antennas Propag. 2013, 61, $4345-4349$.

68. Dayo, Z.A.; Cao, Q.; Soothar, P.; Lodro, M.M.; Li, Y. A compact coplanar waveguide feed bow-tie slot antenna for WIMAX, C and $X$ band applications. In Proceedings of the 2019 IEEE International Conference on Computational Electromagnetics (ICCEM), Shanghai, China, 20-22 March 2019; pp. 1-3. 
69. Awl, H.N.; Abdulkarim, Y.I.; Deng, L.; Bakır, M. Bandwidth improvement in bow-tie microstrip antennas: The effect of substrate type and design dimensions. Appl. Sci. 2020, 10, 504. [CrossRef]

70. Nguyen, C.; Technologies, A.; Schneider, M.V.; Chew, W.C.; Liu, Q.H.; Richards, W.F.; Lo, Y.T.; Harrison, D.D.; Ray, S.; Kumar, G.; et al. A Compact Dual-Polarızed Cavity-Backed Annular Slot. Wiley Microw. Opt. Technol. Lett. 2015, 57, 384-388. [CrossRef]

71. Dastranj, A. Very small planar broadband monopole antenna with hybrid trapezoidal-elliptical radiator. IET Microw. Antennas Propag. 2017, 11, 542-547. [CrossRef]

72. Ju, J.; Jin, L.; Jin, W.; Wang, S.J.; Jia, P.G.; Huang, J.; Lan, X.W.; Wang, H.Z.; Jiang, L.; Xiao, H.; et al. A Novel Compact Uwb Monopole Antenna With Enhanced Bandwidth Using Triangular Defected Microstrip Structure and Stepped Cut Technique. Wiley Microw. Opt. Technol. Lett. 2016, 58, 1561-1563. [CrossRef]

73. Zhang, H.; Guo, Y.; Zhang, W.; Wang, G. A Broadband Crossed-Slot Circularly Polarized Antenna With Stable Phase Center for Gnss Applications. Prog. Electromagn. Res. C 2018, 86, 55-67. [CrossRef]

74. Hu, H.-T.; Chen, F.-C.; Chu, Q.-X. A Wideband U-Shaped Slot Antenna and Its Application in MIMO Terminals. IEEE Antennas Wirel. Propag. Lett. 2015, 15, 508-511. [CrossRef]

75. Jan, J.; Su, J. Bandwidth Enhancement of a Printed Wide-Slot Antenna with a Rotated Slot. IEEE Trans. Antennas Propag. 2005, 53, 2111-2114. [CrossRef]

76. Kumar, B.; Shukla, B.K.; Somkuwar, A.; Raghuvanshi, D.K. A Study of Hybrid Wide Slot Antenna With Hybrid Parasitıc Element for Wideband Applications. Prog. Electromagn. Res. C 2019, 89, 27-38. [CrossRef]

77. Yilmaz, T.; Foster, R.; Hao, Y. Broadband Tissue Mimicking Phantoms and a Patch Resonator for Evaluating Noninvasive Monitoring of Blood Glucose Levels. IEEE Trans. Antennas Propag. 2014, 62, 3064-3075. [CrossRef]

78. Asif, S.M.; Iftikhar, A.; Braaten, B.D.; Khan, M.S. Design of an ultra-wideband antenna using flexible graphene-based conductor sheets. In Proceedings of the 2016 IEEE International Symposium on Antennas and Propagation (APSURSI), Fajardo, PR, USA, June 2016-July 2016; pp. 1863-1864.

79. Aziz, A.A.A.; Abdel-Motagaly, A.T.; Ibrahim, A.A.; El Rouby, W.M.; Abdalla, M. A printed expanded graphite paper based dual band antenna for conformal wireless applications. AEU-Int. J. Electron. Commun. 2019, 110, 152869. [CrossRef]

80. Sa'Don, S.; Jamaluddin, M.; Kamarudin, M.; Ahmad, F.; Yamada, Y.; Kamardin, K.; Idris, I.; Seman, N. Characterisation of tunable graphene antenna. AEU-Int. J. Electron. Commun. 2020, 118, 153170. [CrossRef]

81. Singh, N.; Kumar, S.; Kanaujia, B.K.; Beg, M.T.; Kumar, S. A compact and efficient graphene FET based RF energy harvester for green communication. AEU-Int. J. Electron. Commun. 2020, 115, 153059. [CrossRef]

82. Dash, S.K.K.; Cheng, Q.S.; Barik, R.K.; Khan, T.; Subramanian, K.S. A compact dual-fed highly isolated SIW based self-diplexing antenna. AEU-Int. J. Electron. Commun. 2021, 132, 153613. [CrossRef]

83. Satitchantrakul, T.; Silapunt, R.; Sirivisoot, S. Meander implantable antenna for biomedical wireless communication. In Proceedings of the 2016 IEEE International Symposium on Antennas and Propagation (APSURSI), Fajardo, PR, USA, 26 June-1 July 2016; pp. 1173-1174.

84. Yasir, M.; Savi, P.; Bistarelli, S.; Cataldo, A.; Bozzi, M.; Perregrini, L.; Bellucci, S. A Planar Antenna with Voltage-Controlled Frequency Tuning Based on Few-Layer Graphene. IEEE Antennas Wirel. Propag. Lett. 2017, 16, 2380-2383. [CrossRef]

85. Kirtania, S.G.; Elger, A.W.; Hasan, R.; Wisniewska, A.; Sekhar, K.; Karacolak, T.; Sekhar, P.K. Flexible Antennas: A Review. Micromachines 2020,11,847. [CrossRef]

86. Fang, R.; Song, R.; Zhao, X.; Wang, Z.; Qian, W.; He, D. Compact and Low-Profile UWB Antenna Based on Graphene-Assembled Films for Wearable Applications. Sensors 2020, 20, 2552. [CrossRef]

87. Products \& Services I eSUN 3D Printing Materials. Available online: https:/ /www.esun3d.net/products / (accessed on 20 October 2021).

88. Black Magic 3D Conductive Graphene Composite $1.75 \mathrm{~mm}$-3D Compare Materials. Available online: https://3dcompare.com/ materials / product/black-magic-3d-conductive-graphene-composite-1-75-mm/ (accessed on 20 October 2021).

89. Supermarket, G. Conductive, Graphene, PLA, Flament. Available online: https://graphene-supermarket.com/ConductiveGraphene-PLA-Filament.html (accessed on 2 March 2021).

90. Sheet Resistance and the Calculation of Resistivity or Thickness Relative to Semiconductor Applications. Available online: http: / / four-point-probes.com/sheet-resistance-and-the-calculation-of-resistivity-or-thickness-relative-to-semiconductorapplications / (accessed on 20 July 2021).

91. Understanding Volume Resistivity Measurements. Available online: http:/ / four-point-probes.com/understanding-volumeresistivity-measurements / (accessed on 20 July 2021).

92. Volume Resistivity, vs. Volume Conductivity vs. Surface Resistivity / CAPLINQ BLOG. Available online: https://www.caplinq. com/blog/linqstat-volume-resistivity-vs-volume-conductivity-vs-surface-resistivity_267/ (accessed on 20 July 2021).

93. Balanis, C.A. Antenna Theory: Analysis and Design, 4th ed.; John Wiley \& Sons: Hoboken, NJ, USA, 2015.

94. Zarei, M.; Nazari, F.; Moravvej-Farshi, M.K. Tunable optical isolator using Graphene-photonic crystal-based hybrid system. Phys. Scr. 2021, 96, 095502. [CrossRef]

95. Bagheri, A.; Nazari, F.; Moravvej-Farshi, M.K. Tunable Optical Demultiplexer for Dense Wavelength Division Multiplexing Systems Using Graphene-Silicon Microring Resonators. J. Electron. Mater. 2020, 49, 7410-7419. [CrossRef]

96. Nazari, F.; Izadi, M. Tunable Autler-Townes splitting using graphene-based electro-optic effect. Phys. Lett. A 2018, 382, 1829-1834. [CrossRef]

97. Nazari, F.; Izadi, M. Control of slow/fast light frequency via tunable EIT window. J. Opt. 2019, 21, 115801. [CrossRef] 
98. Azim, R.; Islam, M.T.; Misran, N. Compact Tapered-Shape Slot Antenna forUWBApplications. IEEE Antennas Wirel Propag. Lett. 2011, 10, 1190-1193. [CrossRef]

99. Kim, S.-W.; Choi, D.-Y. Implementation of rectangular slit-inserted ultra-wideband tapered slot antenna. SpringerPlus 2016, 5, 1387. [CrossRef]

100. Jiang, Y.; Yuan, R.; Gao, X.; Wang, J.; Li, S.; Lin, Y.-Y. An ultra-wideband pattern reconfigurable antenna based on graphene coating. Chin. Phys. B 2016, 25, 118402. [CrossRef]

101. Azizi, M.K.; Ksiksi, M.A.; Ajlani, H.; Gharsallah, A.A. Terahertz Graphene-Based Reconfıgurable Patch Antenna. Prog. Electromagn. Res. Lett. 2017, 71, 69-76. [CrossRef]

102. Scidà, A.; Haque, S.; Treossi, E.; Robinson, A.; Smerzi, S.; Ravesi, S.; Borini, S.; Palermo, V. Application of graphene-based flexible antennas in consumer electronic devices. Mater. Today 2018, 21, 223-230. [CrossRef]

103. Dwivedi, R.P.; Kommuri, U.K. Compact high gain UWB antenna using fractal geometry and UWB-AMC. Microw. Opt. Technol. Lett. 2019, 61, 787-793. [CrossRef]

104. Jilani, S.F.; Greinke, B.; Hao, Y.; Alomainy, A. Flexible millimetre-wave frequency reconfigurable antenna for wearable applications in 5G networks. In Proceedings of the 2016 URSI International Symposium on Electromagnetic Theory (EMTS), Espoo, Finland, 14-18 August 2016; pp. 846-848. [CrossRef]

105. Liu, H.; Sun, S.; Wu, L.; Bai, P. Optical Near-Field Enhancement with Graphene Bowtie Antennas. Plasmonics 2014, 9, 845-850. [CrossRef]

106. Lin, Y.-M.; Jenkins, K.A.; Valdes-Garcia, A.; Small, J.P.; Farmer, D.B.; Avouris, P. Operation of Graphene Transistors at Gigahertz Frequencies. Nano Lett. 2009, 9, 422-426. [CrossRef]

107. Gusynin, V.P.; Sharapov, S.; Carbotte, J.P. Magneto-optical conductivity in graphene. J. Physics Condens. Matter 2006, 19. [CrossRef]

108. Hanson, G.W. Dyadic Green's Functions for an Anisotropic, Non-Local Model of Biased Graphene. IEEE Trans. Antennas Propag. 2008, 56, 747-757. [CrossRef]

109. Gómez-Díaz, J.S.; Perruisseau-Carrier, J.; Sharma, P.; Ionescu, A. Non-contact characterization of graphene surface impedance at micro and millimeter waves. J. Appl. Phys. 2012, 111, 114908. [CrossRef]

110. Perruisseau-Carrier, J.; Tamagnone, M.; Gomez-Diaz, J.S.; Carrasco, E. Graphene antennas: Can integration and reconfigurability compensate for the loss? In Proceedings of the 2013 European Microwave Conference, Nuremberg, Germany, 6-10 October 2013; pp. 369-372. 